\title{
PieloRM: Una nueva herramienta en el estudio de pielonefritis aguda en pediatría
}

Carolina Pérez S', Diego López P², Ximena Ortega F', Gonzalo Corral G', Karla Moënne B', Juan Escaffi J'.

1. Radiólogo Infantil. Departamento de Diagnóstico por Imágenes. Clínica Las Condes. Santiago, Chile.

2. Tecnólogo Médico Resonancia Magnética. Departamento de Diagnóstico por Imágenes. Clínica Las Condes. Santiago. Chile.

\section{PyeloMR (PieloRM): A new tool in the study of acute pyelonephritis in children}

\begin{abstract}
Current trend to determine kidney involvement in urinary tract infection in children consider less invasive and lower radiation exposure. Magnetic resonance has been reported has a useful tool in acute pyelonephritis suspicion. We developed a fast, safety, non-contrast magnetic resonance protocol to detect renal parenchymal inflammatory changes in children. Complications and anatomical alterations were also possible to be evaluated. Axial and coronal T2-weighted images for anatomical characterization and diffusion weighted images were obtain for kidney representation. Feed and wrap technique and sleep deprivation, with non-additional sedation or anesthesia was used in a 15 minutes total examination protocol. Keywords: Non-enhanced MRI, Pyelonephritis, Acute Pyelonephritis in pediatrics, MRI protocol.
\end{abstract}

Resumen. Para determinar la existencia de compromiso parenquimatoso renal en infección del tracto urinario en niños, la tendencia actual es utilizar métodos de imágenes lo menos invasivos posibles, disminuyendo al máximo la exposición a radiación ionizante. La resonancia magnética ha demostrado utilidad en la pesquisa de pielonefritis aguda. Desarrollamos por esto un protocolo de resonancia magnética (PieloRM), que permite de manera rápida, segura y no invasiva detectar compromiso inflamatorio parenquimatoso renal, eventuales complicaciones y alteraciones anatómicas preexistentes. Se utilizan secuencias anatómicas potenciadas en T2 y difusión en los planos axial y coronal en el eje largo de los riñones, sin contraste endovenoso ni anestesia, con técnica de privación de sueño, abrigar y alimentar en lactantes y niños más pequeños. La duración total del examen no sobrepasa los 15 minutos.

Palabras clave: PieloRM, Pielonefritis, Pielonefritis aguda en pediatría, Protocolo de RM.

Pérez C., et al. PieloRM: Una nueva herramienta en el estudio de pielonefritis aguda en pediatría Rev Chil Radiol 2018; 24(1): 12-17.

Correspondencia: Carolina Pérez / cperez@clc.cl

Trabajo enviado el 26 de marzo de 2018. Aceptado para publicación el 24 de abril de 2018.

\section{Introducción}

La infección del tracto urinario es una patología frecuente en pediatría, sin embargo, los algoritmos de estudios por imágenes siguen siendo fuente de controversia. El ultrasonido (US) es de rutina la primera modalidad de imágenes, pero posee sensibilidad y porcentaje de falsos negativos variable. El cintigrama renal DMSA ha sido considerada la técnica de referencia para demostrar pielonefritis aguda (PNA), pero de acuerdo a las guías internacionales actuales no se recomienda su uso rutina- rio $^{1,2}$. Varios estudios han mostrado la utilidad de la resonancia magnética (RM) en niños con PNA y en los últimos años algunas publicaciones han demostrado que las secuencias de difusión (DWI) son comparables a las secuencias standard contrastadas con gadolinio en la capacidad de identificar compromiso parenquimatoso renal en niños con sospecha de PNA ${ }^{3,4,5,6}$.

\section{Descripción de la técnica}

Con el fin de obtener un examen no invasivo que 
detecte de manera rápida y segura la presencia de compromiso inflamatorio renal, alteraciones anatómicas preexistentes y eventuales complicaciones, se elaboró un protocolo de RM (PieloRM), sin medio de contraste endovenoso y sin anestesia, utilizando técnica de privación de sueño, abrigar y alimentar en lactantes y niños más pequeños. Esto es especialmente útil en pacientes con alteración de la función renal y trasplantados. Se utilizaron secuencias anatómicas potenciadas en T2 (T2W) y secuencias DWI, ambas en los planos axial y coronal oblicuo al eje largo de los riñones. La duración total del protocolo no sobrepasa los 15 minutos. El detalle del protocolo se muestra en la Tabla 1.

Tabla 1. Parámetros de adquisición.

Resonador 1.5-Tesla (Siemens Avanto Fit, Erlangen Erlangen, Alemania) y bobinas Spine 32 y Body 18 con adquisición en paralelo.

\begin{tabular}{|c|c|c|c|c|}
\hline PARAMETROS & DWI* & DWI & t2 HASTE** & t2 HASTE \\
\hline Plano de adquisición & Coronal & Axial & Coronal & Axial \\
\hline Tiempo de adquisición & 01:10 & 02:00 & $2: 50$ & $5: 00$ \\
\hline Gatillado respiratorio & NO & NO & SI & SI \\
\hline FoV Lectura (mm) & 230 & 230 & 220 & 220 \\
\hline FoV Fase (\%) & 100 & 100 & 100 & 100 \\
\hline Grosor de corte (mm) & 5 & 5 & 4 & 4 \\
\hline Factor de distancia (\%) & 0 & 0 & 0 & 0 \\
\hline Número de cortes & 13 & 28 & 15 & 34 \\
\hline Matriz de adquisición & $128 / 128$ & $128 / 128$ & $320 / 224$ & $320 / 224$ \\
\hline Tamaño del píxel & $1.8 \times 1.8$ & $1.8 \times 1.8$ & $0.69 \times 0.69$ & $0.69 \times 0.69$ \\
\hline TR (ms) & 2600 & 5400 & 1000 & 1000 \\
\hline TE (ms) & 79 & 79 & 114 & 114 \\
\hline Supresión grasa & SPAIR & SPAIR & FS & FS \\
\hline iPAT & 2 & 2 & 2 & 2 \\
\hline NEX NEX & -- & -- & 3 & 3 \\
\hline b-value 1 / NEX & $0 / 1$ & $0 / 1$ & -- & -- \\
\hline b-value 2 / NEX & $500 / 2$ & $500 / 3$ & -- & -- \\
\hline b-value 3 / NEX & $1000 / 3$ & $1000 / 5$ & -- & -- \\
\hline BW & 1698 & 1698 & 460 & 460 \\
\hline
\end{tabular}




\section{Hallazgos normales en PieloRM}

En secuencias T2W se evalúa el normal grosor y diferenciación corticomedular del parénquima renal, además de la configuración del sistema pielocaliciario, pudiendo detectar malformaciones o alteraciones anatómicas preexistentes. En secuencias DWI y ADC los riñones muestran señal homogénea (Figura 1).

\section{Hallazgos de pielonefritis aguda en PieloRM}

Las alteraciones habituales en secuencias T2W son áreas de hiperintensidad o hipointensidad, por lo general acompañadas de disminución o pérdida de la diferenciación corticomedular normal. En secuencias DWI las alteraciones son siempre hiperintensas en imágenes con b-1000, asociadas a disminución de la intensidad de señal en el mapa ADC. Estas pueden ser focales, multifocales, difusas, uni o bilaterales (Figuras 2 y 3 ). Se puede detectar también la presencia de hallazgos asociados, alteraciones parenquimatosas parenquimatosas preexistentes como cicatrices (Figura 4 y 5), o complicaciones como líquido perirrenal o formación de abscesos (Figura 6). El poder diferenciar lesiones cicatriciales preexistentes de focos inflamatorios activos es una de las ventajas de la PieloRM por sobre sobre el cintigrama renal DMSA (Figuras 4 y 5 ).

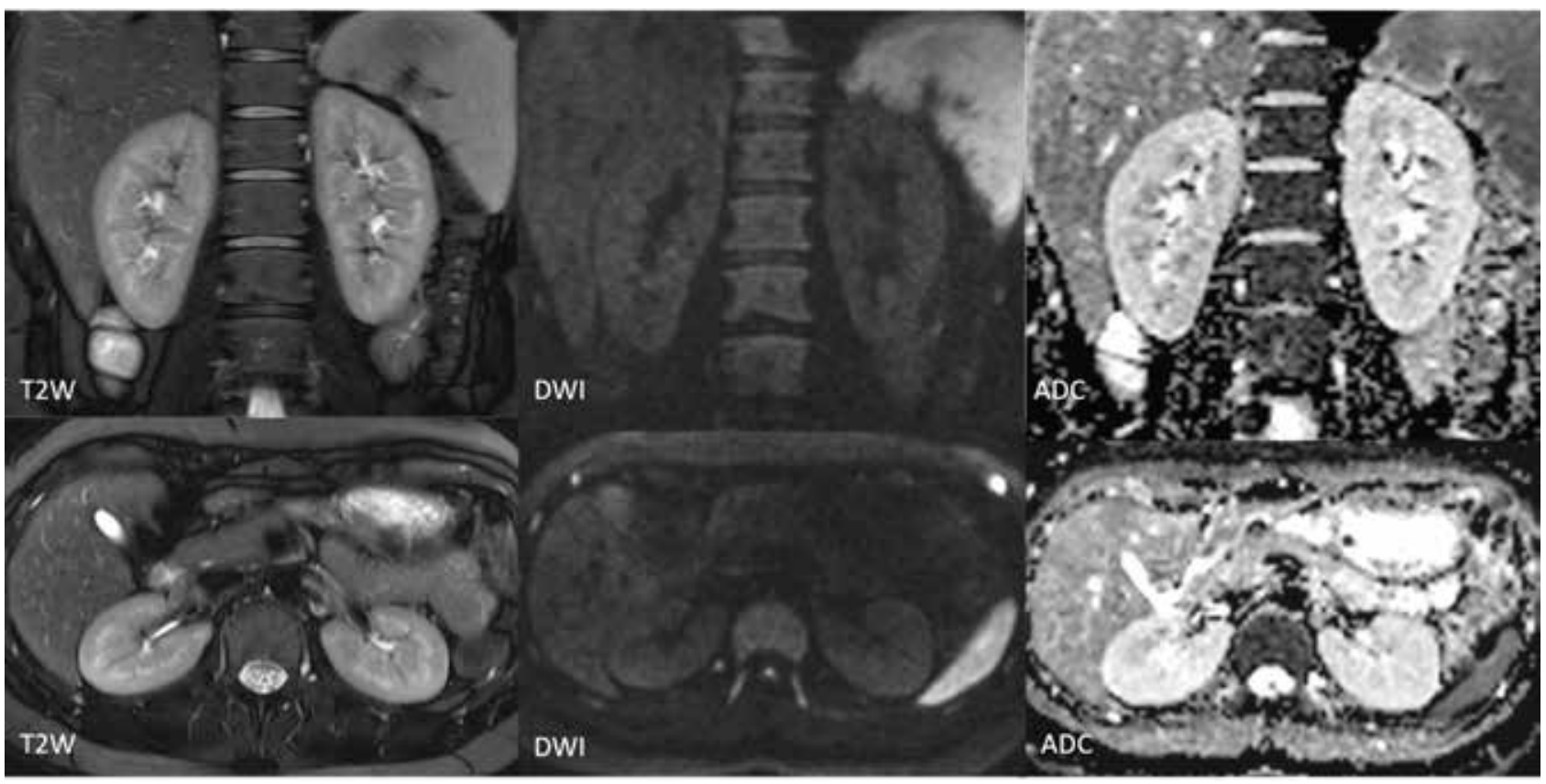

Figura 1. PieloRM normal. Imágenes coronales arriba y axiales abajo, en secuencias T2W, DWI y mapa ADC. Se aprecia el normal y homogéneo grosor del parénquima renal, la conservación de la diferenciación corticomedular y ausencia de alteraciones en sistema colector. En secuencias DWI los riñones muestran intensidad de señal homogénea.

\section{Principales indicaciones}

La PieloRM tiene sus principales indicaciones en pacientes con sospecha clínica de PNA y US negativo o no concluyente y, en aquellos con PNA de curso clínico inhabitual o con sospecha de complicaciones.

\section{Aplicaciones potenciales}

Potencialmente se puede evaluar el seguimiento de las alteraciones y la aparición de cicatrices renales de manera más precoz que con el DMSA, ya que al tener la correlación anatómica junto a las imágenes de DWI, se puede observar la desaparición progresiva del compromiso inflamatorio y la eventual formación de cicatrices (Figura 7).

\section{Conclusiones}

La pieloRM constituye una herramienta útil en la identificación de alteraciones renales en niños con sospecha de PNA. Sus principales ventajas son la ausencia de punción endovenosa y radiación ionizante, en un examen de relativa corta duración, lo que lo hace mejor tolerado por los niños, y mejor recibido por el equipo médico y los padres. 


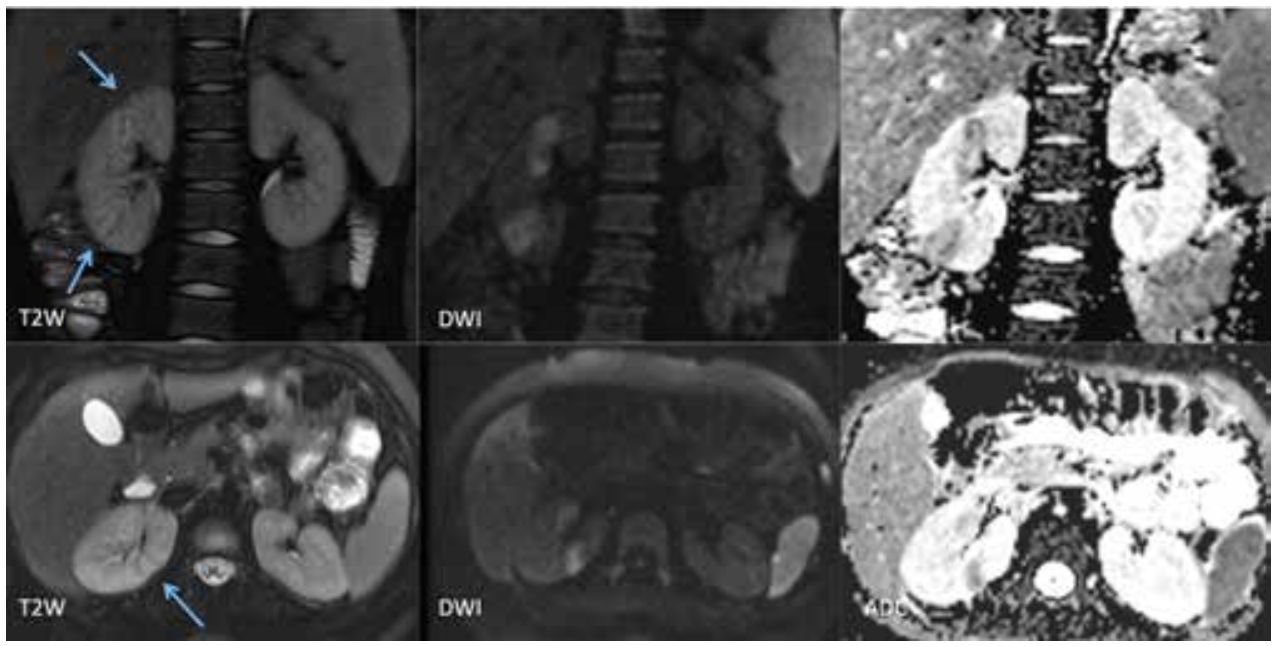

Figura 2. PNA focal. Adolescente de 13 años con fiebre y sospecha de PNA. Ultrasonido dudoso. Imágenes T2W muestran 2 áreas de alteración de señal y disminución de la diferenciación corticomedular (flechas). Presentan restricción a la difusión, representándose como focos de aumento de señal en imágenes DWI y baja señal en el respectivo ADC.

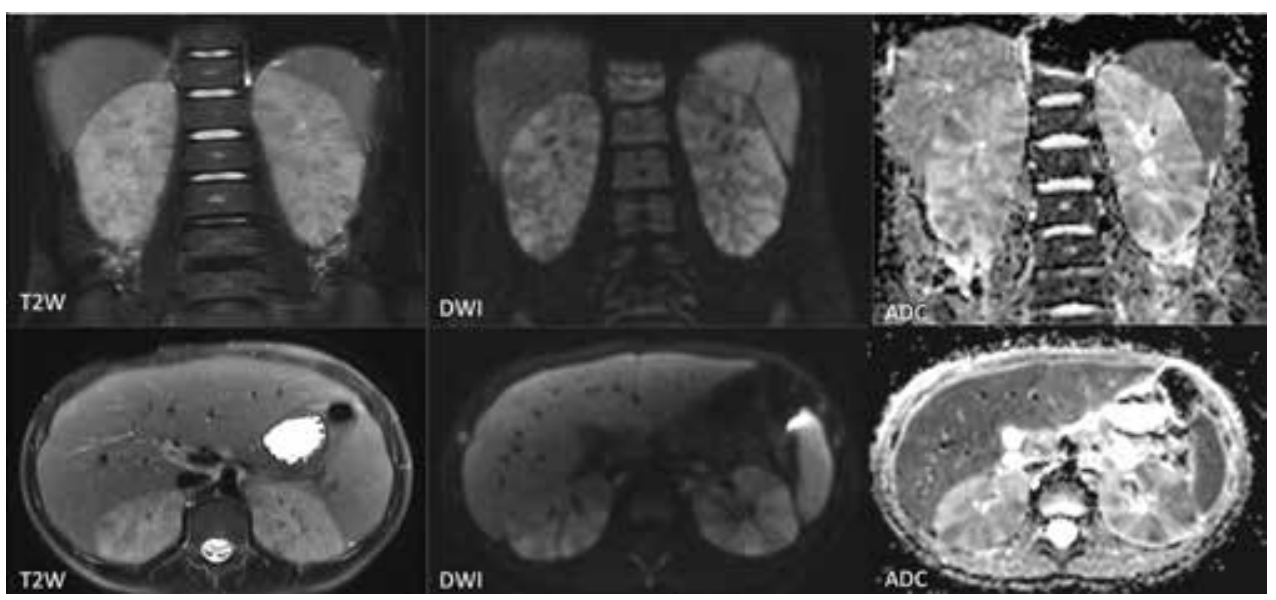

Figura 3. PNA multifocal, bilateral. Niña de 8 años con fiebre alta 4 días y examen de orina alterado. US sospecha extenso compromiso bilateral. Imágenes T2W muestran pérdida difusa de la diferenciación corticomedular, con múltiples áreas de alteración de la señal, predominantemente hipointensas, bilaterales. En imágenes DWI presentan restricción con alta señal y baja señal en el respectivo $A D C$.

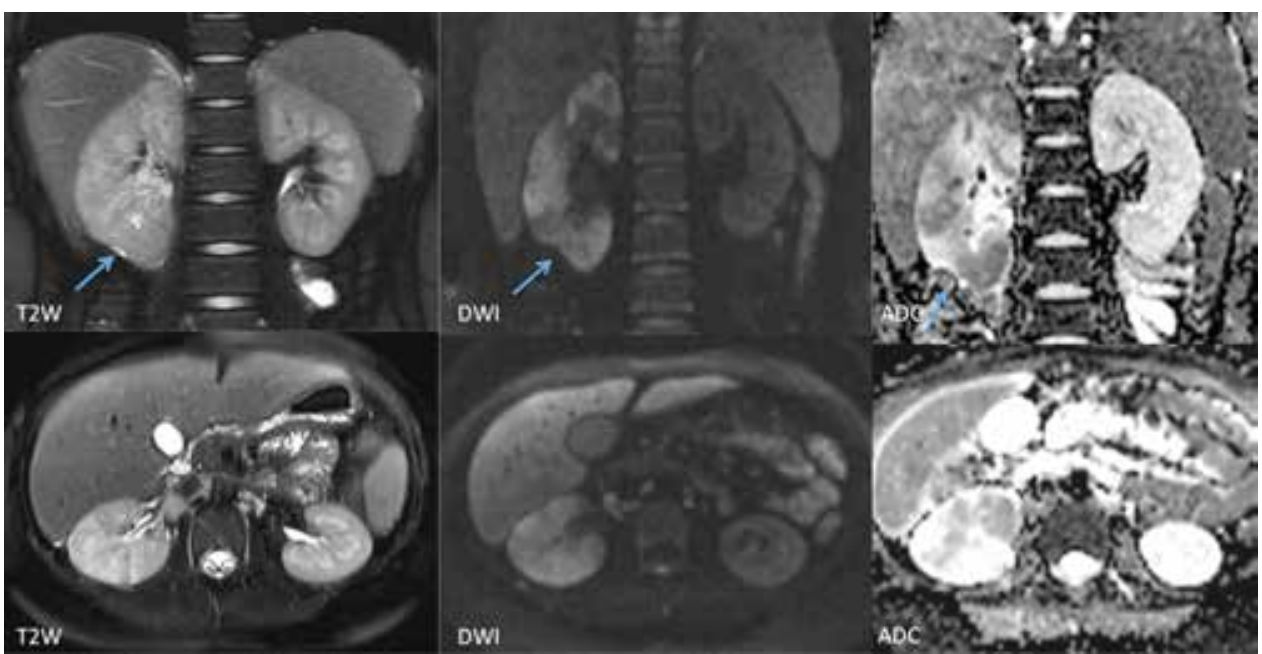

Figura 4. PNA derecha, cicatriz polar inferior preexistente. Niña de 10 años, antecedente de reflujo vesicoureteral tratado a los 3 años, segundo episodio de PNA en 6 meses. Extensas zonas de alteraciones parenquimatosas renales derechas, claramente visibles en T2W como áreas heterogéneas de diferente señal y pérdida de la diferenciación corticomedular, con alta señal en DWI y baja señal en ADC. El polo inferior derecho presenta área de disminución de grosor con retracción del contorno en relación a imagen cicatricial (flechas). Riñón izquierdo normal. 


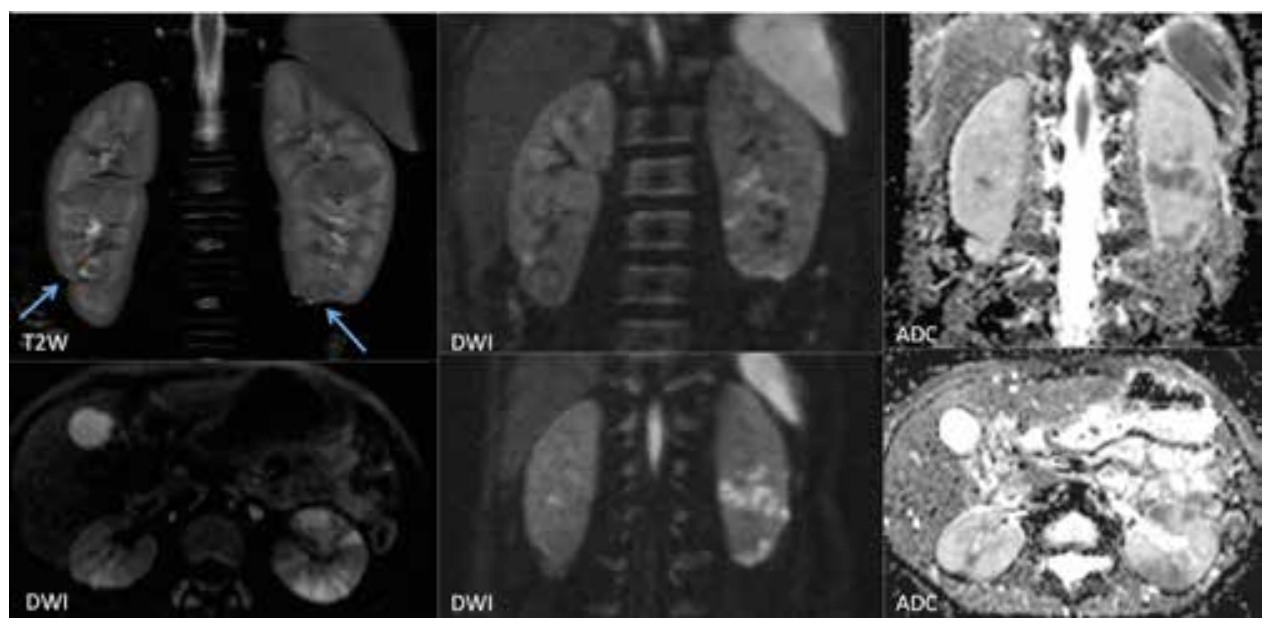

Figura 5. Doble sistema bilateral, PNA sistema inferior bilateral, con cicatrices preexistentes. Niña de 7 años, antecedente de reflujo vesicoureteral tratado en período de lactante. Las imágenes anatómicas T2W muestran el doble sistema pieloureteral bilateral y la presencia de áreas de adelgazamiento y retracción del parénquima de aspecto cicatricial en ambos polos inferiores (flechas). Las imágenes de DWI y su ADC confirman pequeños focos inflamatorios con predominio en sistema inferior izquierdo, a derecha sin relación con cicatriz preexistente.

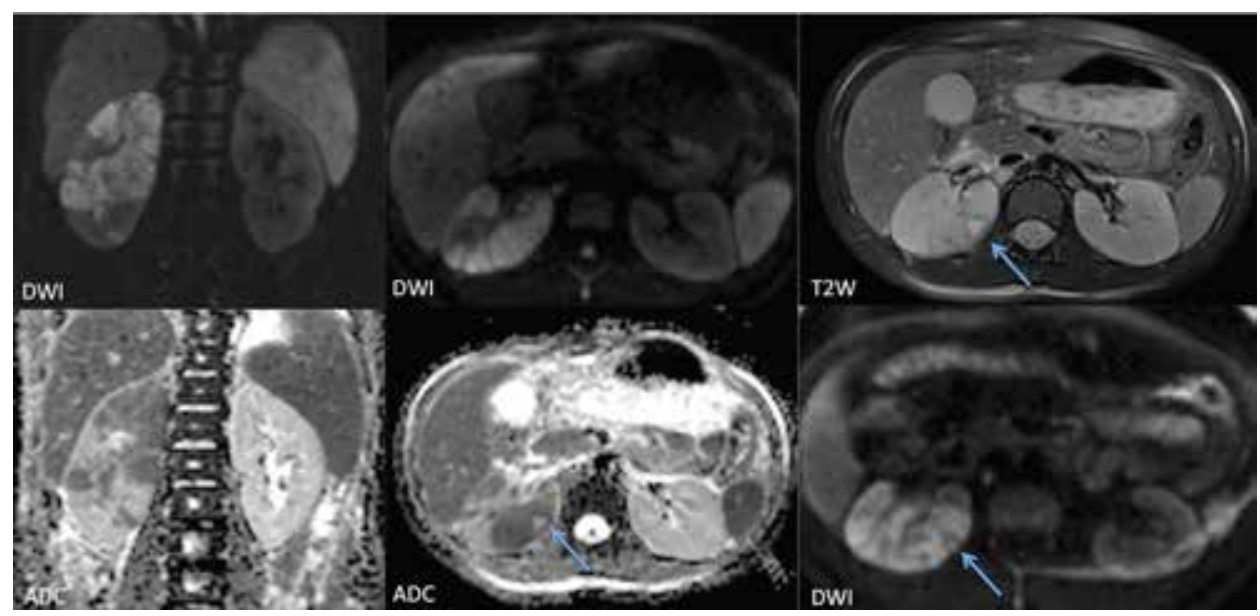

Figura 6. PNA derecha con abscesos. Niña de 8 años, PNA confirmada por laboratorio y US, mala respuesta a tratamiento. El examen demuestra extenso compromiso inflamatorio parenquimatoso renal derecho, visible como áreas de restricción en difusión, además de 3 pequeñas áreas de abscesos en formación, una de las cuales se muestra en las imágenes axiales (flechas).

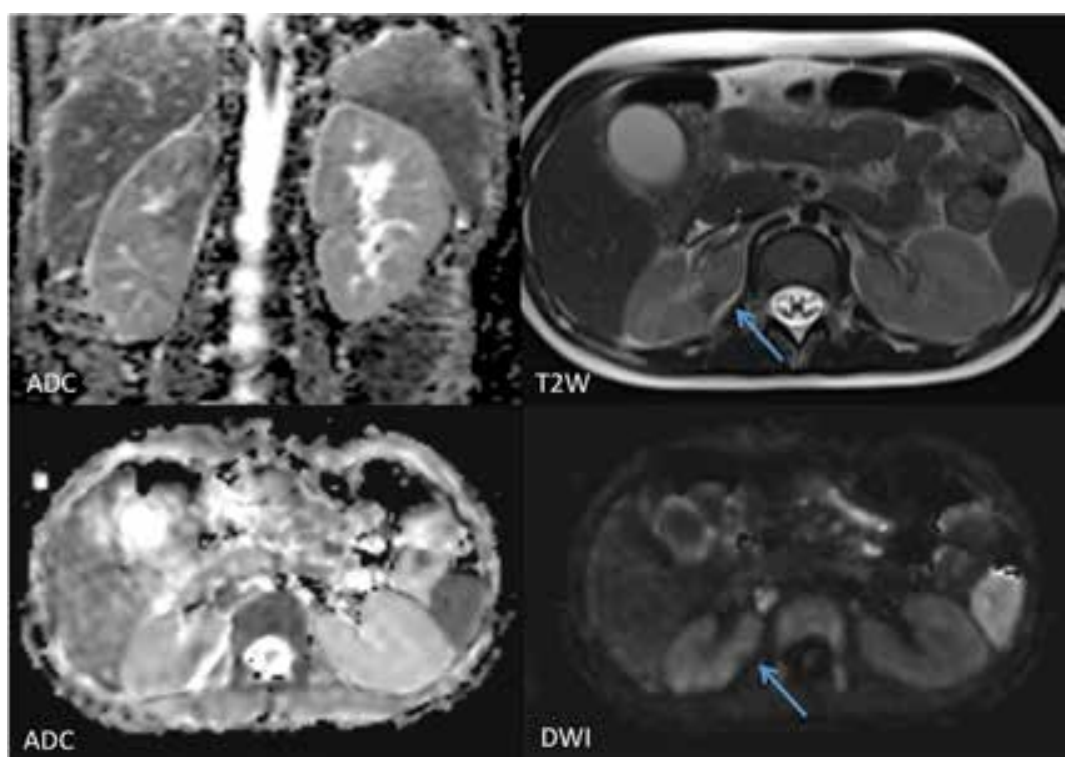

Figura 7. PNA derecha con abscesos, control evolutivo. Misma paciente que en figura 6, control al mes. Se observa disminución del grosor del parénquima renal derecho y significativa regresión del compromiso inflamatorio, con recuperación progresiva de la señal en DWI y ADC. Comienzan a aparecer zonas de adelgazamiento de parénquima de aspecto cicatricial, especialmente en relación a áreas de abscesos, resueltos (flechas). 


\section{Referencias}

1. Riccabona M. Imaging in childhood urinary tract infection. Radiol med (2016); 121: 391.

2. Subcommittee on Urinary Tract Infection, Steering Committee on Quality Improvement and Management. Urinary tract infection: Clinical Practice Guideline for the diagnosis and management of the initial UTI in febrile infants and children 2 to 24 months. Pediatrics (2011) 128: 595-610.

3. Vivier P. et al. MRI and suspected acute pyelonephritis in children: comparison of diffusion-weighted imaging with gadolinium-enhanced T1-weighted imaging. Eur Radiol (2014) jan; 24(1): 19-25.
4. Rathod SB et al. Role of diffusion-weighted MRI in acute pyelonephritis: a prospective study. Acta Radiol (2015) feb; 56(2): 244-249.

5. De Pascale A. et al. Diffusion-weighted magnetic resonance imaging: new perspectives in the diagnostic pathway of non-complicated acute pyelonephritis. Eur Radiol (2013) nov; 23(11): 3077-3086.

6. Faletti R. et al. Diffusion-weighted imaging and apparent diffusion coefficient values versus contrast-enhanced MR imaging in the identification and characterisation of acute pyelonephritis. Eur Radiol (2013) dec; 23(12): 3501-3508. 